\title{
Excess Fluid volume: Clinical Validation in Patients with Decompensated Heart Failure
}

\author{
Quenia Camille Soares Martins ${ }^{1}$ \\ Graziella Badin Aliti \\ Joelza Chisté Linhares ${ }^{3}$ \\ Eneida Rejane Rabelo ${ }^{4}$
}

\begin{abstract}
This cross-sectional study aimed to clinically validate the defining characteristics of the Nursing Diagnosis Excess Fluid Volume in patients with decompensated heart failure. The validation model used follows the model of Fehring. The subjects were 32 patients at a university hospital in Rio Grande do Sul. The average age was $60.5 \pm 14.3$ years old. The defining characteristics with higher reliability index $(R): R \geq 0.80$ were: dyspnea, orthopnea, edema, positive hepatojugular reflex, paroxysmal nocturnal dyspnea, pulmonary congestion and elevated central venous pressure, and minor or secondary, $R>0.50$ to 0.79 : weight gain, hepatomegaly, jugular vein distention, crackles, oliguria, decreased hematocrit and hemoglobin. This study indicates that the defining characteristics with $R>0.50$ and 1 were validated for the diagnosis Excess Fluid Volume.
\end{abstract}

Descriptors: Heart Failure; Nursing Diagnoses; Medical History Taking; Physical Examination.

\footnotetext{
1 RN, M.Sc. in Nursing, Nursing Service Onco-Hematological, Hospital de Clínicas de Porto Alegre, RS, Brazil. E-mail: queniacamille@terra.com.br.

${ }^{2}$ RN, Hospital de Clínicas de Porto Alegre, RS, Brazil. Doctoral Student, Escola de Enfermagem, Universidade Federal do Rio Grande do Sul, RS, Brazil. E-mail: graziella.aliti@gmail.com.

${ }^{3}$ RN, Master's Student, Escola de Enfermagem, Universidade Federal do Rio Grande do Sul, RS, Brazil. E-mail: joelza@gmail.com.

${ }^{4}$ RN, Ph.D. in Biological Sciences. Adjunct Professor, Escola de Enfermagem, Universidade Federal do Rio Grande do Sul, RS, Brazil. E-mail: eneidarabelo@gmail.com.
}

Corresponding Author: Eneida Rejane Rabelo Universidade Federal do Rio Grande do Sul. Escola de Enfermagem Departamento de Enfermagem Médico-Cirurgica Rua São Manoel, 963 Bairro Rio Branco CEP: 90620-910 Porto Alegre. RS, Brasil E-mail: eneidarabelo@gmail.com 


\title{
Volume de líquidos excessivo: validação clínica em pacientes com insuficiência cardíaca descompensada
}

Estudo transversal que teve como objetivo validar clinicamente as características definidoras do diagnóstico de enfermagem volume de líquidos excessivo, em pacientes com insuficiência cardíaca descompensada. Para a validação, utilizou-se o modelo de Fehring. Participaram 32 pacientes de um hospital universitário do Rio Grande do Sul. A média de idade foi de $60,5 \pm 14,3$ anos. As características definidoras maiores com taxa de fidedignidade(R): $R \geq 0,80$ foram: dispneia, ortopneia, edema, refluxo hepatojugular positivo, dispneia paroxística noturna, congestão pulmonar e pressão venosa central elevada; e menores, ou secundárias, $\mathrm{R}>0,50$ a 0,79: ganho de peso, hepatomegalia, distenção da veia jugular, crepitações, oligúria, hematócrito e hemoglobina diminuídos. Demonstrou-se, neste estudo, que as características definidoras com R >0,50 e 1 foram validadas para o diagnóstico volume de líquidos excessivo na amostra em estudo.

Descritores: Insuficiência Cardíaca; Diagnóstico de Enfermagem; Anamnese; Exame Físico.

\section{Volumen de líquidos excesivo: validación clínica del diagnóstico en pacientes con insuficiencia cardíaca descompensada}

\begin{abstract}
Estudio transversal que tuvo como objetivo validar clínicamente las características definidoras del Diagnóstico de Enfermería Volumen de Líquidos Excesivo en pacientes con insuficiencia cardíaca descompensada. Para la validación se utilizó el modelo de Fehring. Participaron 32 pacientes de un hospital universitario en Rio Grande del Sur. El promedio de edad fue de $60,5 \pm 14,3$ años. Las características definidoras mayores que tuvieron tasa de fiabilidad $(R)$ : $R \geq 0,80$ fueron: disnea, orto-disnea, edema, reflujo hepatoyugular positivo, disnea paroxística nocturna, congestión pulmonar y presión venosa central elevada; y las menores o secundarias con $R>0,50$ a 0,79, fueron: aumento de peso, hepatomegalia, distención de la vena yugular, crepitaciones, oliguria, hematocrito y hemoglobina disminuidos. Se demostró en este estudio que las características definidoras con $\mathrm{R}>0,50$ y 1 fueron validadas para el diagnóstico Volumen de Líquidos Excesivo en la muestra en estudio.
\end{abstract}

Descriptores: Insuficiencia Cardiaca; Diagnóstico de Enfermería; Anamnesis; Examen Físico.

\section{Introduction}

Heart failure (HF) is a chronic illness with alarming morbidity and mortality impacts ${ }^{(1)}$. Although studies indicate that HF prognoses have improved due to the optimization of medication treatment, electronic devices and patient follow-up by multidisciplinary teams, these patients' evolution is still unfavorable in terms of rehospitalizations ${ }^{(2-3)}$.

A recent study conducted in Brazil demonstrated that the most common clinical manifestations in patients admitted at emergency units are related to congestion and hypertension episodes(3).
In this context, patient admission to emergency rooms demands efficient, fast and safe assessment by physicians and nurses. Early recognition of the clinical situation determines and orients the most adequate interventions for patients ${ }^{(4)}$. In this perspective, a recent study stands out, aimed at comparing the clinical assessment of congestion by a nurse and by cardiologists, correlating their assessments with N-terminal BNP (NTproBNP) levels. The results of that research suggest that a specialist nurse trained in HF obtained a similar performance to that of cardiologists to detect congestion 
and assess the hemodynamic profile of patients with chronic $\mathrm{HF}^{(5)}$.

In clinical practice, it is observed that, at many institutions, nurses are responsible for patient screening at emergency units. Thus, the accomplishment of the nursing process phases will benefit the establishment of a priority nursing diagnosis related to the clinical manifestations present in congestion patients( ${ }^{(6)}$. In this context, clinical nursing assessment will permit the establishment of the diagnosis Excess Fluid Volume, directly related with pulmonary and systemic congestion.

In the scenario of research on the nursing diagnosis Excess Fluid Volume, a study stands out that identified the defining characteristics in the context of HF patients. In that documentary retrospective study of 30 patients' records, the characteristics related to the diagnosis were pulmonary crackles, increased pulmonary capillary pressure, dyspnea and decreased vesicular murmur(7). Also, a descriptive and exploratory research included 29 patients, selected by two expert nurses and divided in two groups: with (nine patients) and without a diagnosis (20 patients). Results from the patient group with the diagnosis identified the following defining characteristics: edema, orthopnea, blood pressure variation, positive fluid balance, change in breathing pattern, central venous pressure variation and electrolyte alteration. The two experts agreed on patients with and without a diagnosis $^{(8)}$.

Based on the research findings in literature so far, a gap is evidenced regarding clinical validation studies for this diagnosis. The relevance of clinical validation studies in different contexts permits establishing priority nursing diagnoses and, mainly, determining conducts based on the best evidence. Although nursing interventions and outcomes for patients with cardiovascular patients with the Excess Fluid Volume diagnosis have recently been

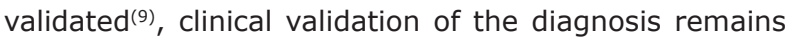
unexplored in the context of HF.

\section{Aim}

To clinically validate the defining characteristics of the diagnosis Excess Fluid Volume in patients with decompensated HF.

\section{Methods}

A prospective and cross-sectional study was accomplished between January and June 2007 at a university hospital in Porto Alegre, Rio Grande do Sul, Brazil. The sample comprised patients diagnosed with class III or IV decompensated HF, according to the New York Heart Association (NYHA) classification(10). For the study, male and female patients were included, aged 18 years or older, hospitalized within six hours at the emergency units, Intensive Care Unit (ICU) and Hospitalization Wards. Patients could manifest systolic or diastolic ventricular dysfunction and should score eight ore more points, according to the Boston criteria for decompensated HF diagnosis. To obtain these criteria, data were assessed from the clinical history, physical examination and radiological findings(11). Patients with acute HF were excluded (post-acute myocardial infarction, secondary to sepsis or patients submitted to coronary graft surgery in the last 30 days).

To validate the defining characteristics, Fehring's clinical validation model was followed. Clinical validation is based on the search for evidence for a given diagnosis starting from the actual clinical environment, in which data are obtained through direct assessment of patients' responses. This model defines that two expert clinical nurses assess a certain number of patients with a pre-established diagnosis; for each of the patients, both experts individually assess the presence or absence of each of the defining characteristics of the diagnosis; and finally, the inter-rater reliability index $(R)$ is calculated for each characteristic. According to that method, characteristics with $\mathrm{R} \geq 0.80$ are considered primary or major, while those with $\mathrm{R}>0.50$ to 0.79 are considered secondary or minor ${ }^{(12)}$. One of the experts in this study had doctored, while the other held a Master's degree in cardiology, both with relevant scientific production, addressing both heart failure and the nursing process. In addition, both had proven clinical experience of more than eight years in care delivery to HF patients. Clinical patient assessment took place at two distinct times, at intervals of less than 10 minutes between one examination and the other.

The first data collection instrument systemizes the patient's initial clinical assessment, aimed at establishing the decompensated HF diagnosis upon hospital admission through the Boston criteria and functional class(11). To assess these criteria, data were used from the clinical history, physical examination and chest $x$-ray. The second instrument covers demographic (age, gender and color) and clinical data (NYHA functional class, 
comorbidities, cause of decompensated $\mathrm{HF}$, weight, blood pressure, heart frequency and alteration on chest $x$-ray), besides questions related to the presence of the defining characteristics for the diagnosis Excess Fluid Volume. Dry weight was based on the patient's information regarding usual weight (before the start of the decompensation symptoms and afterwards checked with the weight verified during outpatient appointments for patients monitored at the institution) and current weight was checked when the patient was included in the study. Pharmacological adherence was self-referred (according to the patients' answers on the regular intake or not of prescribed drugs) and non-pharmacological adherence was assessed through answers regarding self-care (sodium and fluid intake restriction, daily weight measurement and physical exercise). Questions related to non-pharmacological adherence had already been used in a previous study by the same research group $^{(13)}$.

Approval for this study was obtained from the Institutional Review Board under number 06-632. Patients received full information on the study aims and were included after signing the Informed Consent Term.

\section{Statistical analysis}

Data were analyzed using Statistical Package for Social Sciences software version 14.0. Categorical variables were described with absolute and relative frequencies, while continuous variables were described as mean and standard deviation or median and interquartile interval. To calculate the inter-rater reliability index for each defining characteristic, the following formula was used:

$$
R=\frac{A}{A+D} \times \frac{F 1 / N+F 2 / N}{2}
$$

Where $A=$ number of agreements; $D=$ number of disagreements; $F 1=$ frequency of characteristics observed by first observer; $\mathrm{F} 2=$ frequency of characteristics observed by second observer; $\mathrm{N}=$ number of subjects observed; and $\mathrm{R}=$ inter-rater reliability index ${ }^{(12)}$.

\section{Results}

Thirty-two patients diagnosed with decompensated HF were included, with a mean age of $60.5+14.3$ years, 17 (53\%) of whom were men. The predominant functional class was III. It was observed that the main cause of decompensated $\mathrm{HF}$ was lack of treatment adherence 20 (62.5\%). Data are shown in Table 1.

Table 1 - Characteristics of decompensated heart failure patient sample, Porto Alegre, Brazil, 2007

\begin{tabular}{lc}
\hline \multicolumn{1}{c}{ Characteristics } & $\mathbf{n = 3 2}$ \\
\hline Age (years) * & $60.5 \pm 14.3$ \\
Gender (male) & $17(53)$ \\
Color (white) & $19(59)$ \\
Functional class III (New York Heart Association) & $20(62.5)$ \\
Functional class IV (New York Heart Association) & $12(37.5)$ \\
Left ventricular ejection fraction (\%) & $31 \pm 11.5$ \\
X-Ray alteration (bilateral pleural effusion) & $17(53)$ \\
Cause of decompensation - lack of adherence & $20(62.5)$ \\
Comorbidities (two or more) & $27(84)$ \\
Boston criteria (10 or more points) & $19(59)$ \\
Dry weight Kg* & $71.5 \pm 19.5$ \\
Weight gain Kg ${ }^{\dagger}$ & $4.5(1.4-7.6)$ \\
Current weight Kg* & $74.5 \pm 19.5$ \\
Systolic blood pressure mmHg* & $118 \pm 30.5$ \\
Diastolic blood pressure mmHg* & $82 \pm 21$ \\
Heart frequency bpm* & $84 \pm 12.5$ \\
\hline
\end{tabular}

Categorical data presented as $\mathrm{n}(\%)$; "Variable expressed as mean \pm standard deviation; ${ }^{+}$Variable expressed as median and 25-75 percentiles.

\section{Defining characteristics of ND Excess Fluid Volume}

Table 2 illustrates the inter-rater reliability index. To validate this diagnosis, 32 patients were assessed, from whom seven major $(R \geq 0.80)$ and six minor defining characteristics ( $R>0.50$ to 0.79 ) were obtained.

Table 2 - Inter-Rater Reliability Index for defining characteristics of ND Excess Fluid Volume, Porto Alegre, Brasil, 2007

\begin{tabular}{ll}
\hline \multicolumn{1}{c}{ Defining Characteristics } & Reliability Index (R) \\
\hline Major or Primary $(\mathrm{R} \geq 0.80)$ & 0.97 \\
Dyspnea & 0.95 \\
Orthopnea & 0.91 \\
Edema & 0.90 \\
Positive hepatojugular reflex & 0.88 \\
Nocturnal paroxysmal dyspnea & 0.87 \\
Pulmonary congestion & 0.85 \\
Elevated central venous pressure & \\
Minor or secondary (R > 0.50 to 0.79) & 0.79 \\
Weight gain & 0.78 \\
Hepatomegaly & 0.76 \\
Jugular vein distention & 0.66 \\
Crackles & 0.63 \\
Oliguria & 0.51 \\
Decreased hemoglobin and hematocrit & \\
\hline
\end{tabular}




\section{Discussion}

This is the first clinical validation study for the ND Excess Fluid Volume in the context of decompensated HF patients.

The sample of 32 patients included white men between 46 and 79 years of age, admitted to the emergency service with a high score on decompensated HF diagnostic criteria. The patients displayed clear functional limitation at the moment of the assessment, severe ventricular dysfunction, presence of pleural effusion, besides other comorbidities. The majority decompensated due to bad treatment adherence.

The primary or major defining characteristics dyspnea, orthopnea, edema, hepatojugular reflex, pulmonary congestion and elevated central venous pressure were identified as the main clinical indicators for the diagnosis Excess Fluid Volume. These signs and symptoms picture the manifestations decompensated patients most commonly present and are mainly related to congestive episodes, with $80.7 \%$ in patients admitted to emergency units ${ }^{(3)}$.

The defining characteristic dyspnea was considered one of the most important to validate the diagnosis under analysis and obtained the highest inter-rater reliability index. This is one of the most common symptoms among HF patients ${ }^{(14)}$ and can be directly associated with pulmonary congestion ${ }^{(15)}$. Similar results were also demonstrated in a retrospective study of congestive HF patients, in which dyspnea was one of the most expressive defining characteristics, identified in $93.3 \%$ of patients( ${ }^{(7)}$.

The defining characteristic orthopnea is associated with frequent hospitalizations, disability to improve the ventricular ejection fraction and has been a symptom capable of identifying groups of people with a worse long-term prognosis(16). In a content validation study of this same diagnosis, orthopnea was also evidenced as one of the primary characteristics ${ }^{(17)}$.

The presence of edema is a common finding in patients diagnosed with decompensated $\mathrm{HF}^{(18)}$. Similar results in the same content validation of this diagnosis classified edema as a major characteristic(17). The defining characteristic edema is a relevant clinical finding in the assessment. Its importance is highlighted in a publication that evidenced that the presence of peripheral edema and hepatojugular reflex in patients with systolic HF were clinical signs capable of defining different pressure levels in the right heart chamber ${ }^{(19)}$, which are useful to stratify prognoses in this syndrome.
Thus, the presence of edema in HF patients appoints the need for a detailed assessment, seeking other signs of congestion that can support a precise clinical decision.

The identification of the presence of positive hepatojugular reflex is an alteration that reflects the right ventricle's disability to adapt to the greater blood volume it is offered during the congested liver's compression(20). In patients with HF and dyspnea, the hepatojugular reflux is a clinical predictor successfully used to identify congestive $\mathrm{HF}^{(19)}$. In an exploratory and descriptive study developed at an institution specialized in patients with cardiovascular diseases, the researchers attempted to detect 61 nurses' use of and importance attributed to the defining characteristics of the diagnosis Excess Fluid Volume. Hepatojugular reflex scored high in the importance category, with 3.89 on a scale ranging from 1 to 5 points ${ }^{(21)}$. In that research, the important relation between hepatojugular reflex and the Excess Fluid Volume diagnosis could be observed.

The defining characteristic nocturnal paroxysmal dyspnea is another symptoms frequently associated with HF. In these cases, during sleep, the peripheral edema is reabsorbed, leading to systemic and pulmonary hypervolemia, with consequent worsening of pulmonary congestion and emergence of nocturnal paroxysmal dyspnea ${ }^{(14,20)}$. In studies on the Excess Fluid Volume diagnosis, this characteristic was not mentioned. The characteristic nocturnal paroxysmal dyspnea was an important clinical symptom to validate that diagnosis, as it revealed to be a complaint different patients manifested. It should be highlighted that this symptom does not figure among the defining characteristics present in the North American Nursing Diagnosis Association's (NANDA-I) classification, but was considered a primary characteristic in the present study.

Evidence of pulmonary congestion was also validated in this study. In this context, a research assessed mortality during one year in patients hospitalized with acute HF and the authors demonstrated that pulmonary congestion was the most common symptom in the sample, present in $63.5 \%$ of cases assessed(22). In the results of a study performed at an institution specialized in cardiovascular patients, the nurses who participated in the study described pulmonary congestion with above-average scores in the category 'use of defining characteristics', corresponding to 4.35 on a scale from 1 to 5 points $^{(21)}$. Besides, in a content validation study of this nursing diagnosis, it was observed that this was one of the primary characteristics(17). In the present research, the characteristic pulmonary congestion was 
assessed through an x-ray, highlighting the importance of equipping nurses to interpret this finding.

Finally, the validation of the defining characteristic elevated central venous pressure also highlights its primary nature. In this study, this measure was assessed through the estimated central venous pressure technique, obtained through jugular distention inspection and measurement(23). The findings of this physical examination method can be extremely useful in clinical practice, as it is a feasible and low-cost means to support the assessment of hemodynamic conditions, especially in critical patients(24). In a study of a group of cardiovascular patients, in which nurses detected the use and importance granted to the defining characteristics of the diagnosis Excess Fluid Volume, it was verified that increased central venous pressure figures among aboveaverage characteristics, scoring $3.84^{(21)}$. In another study, central venous pressure variations were defined as one of the minor defining characteristics, identified in $55.5 \%$ of patients diagnosed with Excess Fluid Volume by expert 1 and in $66.6 \%$ of patients by expert $2^{(23)}$. This characteristic was also mentioned among the major characteristics observed in the content validation study of this diagnosis ${ }^{(17)}$.

Validated secondary characteristics include weight gain within a short time period, hepatomegaly, jugular vein distention, crackles, oliguria and decreased hematocrit and hemoglobin.

Weight gain within a short time period was already investigated in a content validation study, where it was classified as a primary characteristic of the study diagnosis ${ }^{(17)}$. In another research on the use and importance of the defining characteristics in cardiovascular patients, nurses mentioned weight in these two categories, scoring 4.36 and 4.31, respectively, on a numerical scale from 1 to $5^{(21)}$. It should be highlighted that weight gain is directly related with the development of congestive episodes, culminating in fluid accumulation, which is reflected in weight gain. A hardly perceptible $10 \%$ increase in total body weight may occur until the edema becomes evident(25).

In this study, hepatomegaly was also verified, a symptom associated with venous hepatic congestion in $\mathrm{HF}$, and more frequently related with congestive episodes due to right $\mathrm{HF}^{(20,23)}$. Although hepatomegaly has not been described in the list of defining characteristics NANDA-I proposed for the diagnosis Excess Fluid Volume, until date, nor has it been mentioned in any research on the theme, the researchers suggest including this signal in the list of defining characteristics, based on the physiopathological relevance of liver distention and also on evidence found in the present study.

Pulmonary crackles were classified as a secondary defining characteristics. Often due to compensatory lymphatic drainage in chronic congestive HF patients, crackles are absent in more than $80 \%$ of cases, despite increased filling pressures. Nevertheless, data found in the present research reinforce literature evidence, identifying the constant presence of this clinical finding in HF patients diagnosed with Excess Fluid Volume. In a retrospective study, crackles were identified in $96.6 \%$ of congestive HF patients( ${ }^{(7)}$. This clinical finding was also observed in a content validation study that described it as a major defining characteristic ${ }^{(17)}$, particularly in the categories 'use' (4.56) and 'importance' (4.63), with scores ranging from 1 to 5 , according to nurses ${ }^{(21)}$.

Finally, oliguria, decreased hemoglobin and hematocritcompletethesecondarydefining characteristics identified in this study. In a content validation research, oliguria was considered a primary defining characteristic, while decreased hemoglobin and hematocrit were defined as secondary characteristics ${ }^{(17)}$.

\section{Conclusions}

This was the first study in a clinical context that validated the defining characteristics of the diagnosis Excess Fluid Volume is decompensated HF patients. The following were validated as primary or major characteristics: dyspnea, orthopnea, edema, positive hepatojugular reflex, nocturnal paroxysmal dyspnea, pulmonary congestion and increased central venous pressure; minor or secondary characteristics: weight gain, hepatomegaly, jugular vein distention, crackles, oliguria and decreased hemoglobin and hematocrit.

It is highlighted that two characteristics, nocturnal paroxysmal dyspnea and hepatomegaly, were clinically relevant to validate this diagnosis. Therefore, their inclusion into the current defining characteristics in the NANDA-I taxonomy is suggested.

The defining characteristics azotemia, intake exceeds output, reduced breath sounds, S3 heart sound and change in mental status scored less than 0.50 and were ignored for the diagnosis.

\section{Implications for Clinical Practice}

The validation of nursing diagnoses based on data directly observed in the clinical environment and determined by expert nurses can contribute to improve the accuracy of other phases in the nursing process and, therefore, offer further benefits for patient care. 
These study results contribute to enhance diagnostic accuracy when decompensated HF patients are admitted and, hence, to direct the most adequate interventions.

\section{References}

1. Cleland JG, Khand A, ClarkA. The heart failure epidemic: exactly how big is it? Eur Heart J. 2001;22:623-6.

2. Barreto ACP, Del Carmo CH, Cardoso JN, Morgado PC, Munhoz RT, Eid MO, et al. Re-hospitalizações e morte por insuficiência cardíaca - Índices ainda alarmantes. Arq Bras Cardiol. 2008;91:335-41.

3. Mangini S, Silveira SF, Silva CP, Grativvol PS, Seguro LFBC, Ferreira SMA, et al Insuficiência cardíaca descompensada na unidade de emergência de hospital especializado em cardiologia. Arq Bras Cardiol. 2008;90(6):400-6.

4. Nohria A, Tsang SW, Fang JC, Lewis EF, Jarcho JA, Mudge $\mathrm{GH}$, et al. Clinical assessment identifies hemodynamic profiles that predict outcomes in patients admitted with heart failure. J Am Coll Cardiol. 2003;41(10):1797-804.

5. Sauer J, Rabelo ER, Castro RA, Goldraich L, Rhode LE, Clausell N, Beck-da-Silva L. Nurses' performance in classifying heart failure patients based on physical exam: comparison with cardiologist's physical exam and levels of N-terminal pro-B-type natriuretic peptide. J Clin Nurs. 2010;19 (23-24):3381-9.

6. Lunney M. Critical thinking and accuracy of nurses' diagnoses. Int J Nurs Terminol Classific. 2003;14(3):96107.

7. Rocha PCS, Maria VLR. Excesso no volume de líquidos pulmonares: diagnóstico de enfermagem. Rev Enferm UERJ. 1996;4(2):183-90.

8. Guimarães HQCP, Barros ALBL, Gutierrez MGR. Identificação das características definidoras do diagnóstico de enfermagem Excesso no Volume de Líquidos. Rev. Latino-Am. Enfermagem. 2000;8(2):6873.

9. Lopes JL, Barros ALBL, Michel JLM. A pilot study to validate the priority nursing interventions classification interventions and nursing outcomes classification outcomes for the nursing diagnosis "Excess fluid volume" in cardiac patients. Int J Nurs Terminol Classific. 2009;20(2):76-88.

10. Dickstein K, Cohen-Solal A, Filippatos G, McMurray JJV, Ponikowski P, Poole-Wilson PA, et al. ESC Guidelines for the diagnosis and treatment of acute and chronic heart failure: The Task Force for the Diagnosis and Treatment of Acute and Chronic Heart Failure 2008. European Society of Cardiology. Eur Heart J. 2008;29(19):2388-442.
11. Carlson KJ, Lee DC, Goroll AH, Leahy M, Johnson

RA. An analysis of physicians' reasons for prescribing long-term digitalis therapy in outpatients. J Chronic Dis. 1985;38(9):733-9.

12. Fehring R. Methods to validate nursing diagnoses. Heart \& Lung. 1987;16(6):625-9.

13. Castro RA, Aliti GB, Linhares JC, Rabelo ER. Adesão ao tratamento de pacientes com insuficiência cardíaca em um hospital universitário. Rev Gaúcha Enferm. 2010;31(2):225-31.

14. Shiber J R, Santana J. Dyspnea. Med Clin N Am. 2006;90:453-79.

15. Maisel A, Hollander JE, Guss D, McCullough P, Nowak $R$, Green $G$, et al. Primary results of the rapid emergency department heart failure outpatient trial (REDHOT). A multicenter study of B-type natriuretic peptide levels, emergency department decision making, and outcomes in patients presenting with shortness of breath. J Am Coll Cardiol. 2004;44(6):1328-33.

16. Beck da Silva L, Mielniczuk L, Laberge M, Anselm A, Fraser M, Williams K. Persistent orthopnea and the prognosis of patients in the heart failure clinic. Congest Heart Fail. 2004;10:177-80.

17. Serget E. Diagnostic content validity of fluid volume excess: a construct replication. In: NANDA, editor. Nursing Diagnoses Proceedings of Ninth Conference; 1990; Philadelphia: Lippincott; 1990.

18. Wender OCB, Boustany SM. Exame do sistema vascular periférico. In: Barros EJG, Albuquerque GC, Pinheiro CTS, Czepielewski MA, editores. Exame Clínico. Porto Alegre (RS): Artmed; 2005.p. 289-98.

19. Rohde LE, Beck-da-Silva L, Goldraich L, Grazziotin TC, Palombini DV, Polanczyk CA, et al. Reliability and prognostic value of traditional signs and symptoms in outpatients with congestive heart failure. Can J Cardiol. 2004;20(7):697-702.

20. Oliveira JG. Insuficiência cardíaca congestiva. In: Porto CC, editor. Doenças do coração prevenção e tratamento. 2 ed. Rio de Janeiro (RJ): Guanabara Koogan; 2005. p. 264-78.

21. Boery RNS, Barros ALBL, Lucena AF. Características definidoras do diagnóstico de enfermagem Volume de Líquidos Excessivo. Rev Gaúch Enferm. 2005;26(3):326-32.

22. Rohde LE, Goldraich L, Polanczyk CA, Borges AP, Biolo A, Rabelo $E$, et al. A simple clinically based predictive rule for heart failure in-hospital mortality. J Card Fail. 2006;12(8):587-93. 
23. Biolo A, Netto R, Dora JM, Polanczyk CA. Exame do sistema cardiovascular. In: Barros EJG, Albuquerque GC, Pinheiro CTS, Czepielewski MA, editores. Exame Clínico: consulta rápida. Porto Alegre (RS): Artmed; 2005. p. 163-82.

24. Vinayak AG, Levitt J, Gehlbach B, Pohlman AS, Hall JB, Kress JP. Usefulness of the external jugular vein examination in detecting abnormal central venous pressure in critically ill patients. Arch Intern Med. 2006; 166(9):2132-7.

25. Cotter G, Felker GM, Adams KF, Milo-Cotter O, O'Connor CM. The pathophysiology of acute heart failure-Is it all about fluid accumulation? Am Heart J. 2008; 155:9-18. 